\title{
Justification of Physical and Verbal Aggression in Uruguayan Children and Adolescents
}

\author{
Natalia E. Fares ${ }^{1, *}$, J. Martin Ramirez ${ }^{2}$, José M. Cabrera ${ }^{3}$, Fernanda Lozano ${ }^{4}$ and Fernando Salas ${ }^{5}$ \\ ${ }^{I}$ Sociopsychobiology of Aggression Research Group, Psychobiology Department \& Institute for Biofunctional Studies, \\ Universidad Complutense de Madrid (UCM), Spain \\ ${ }^{2}$ Sociopsychobiology of Aggression Research Group, Psychobiology Department \& Institute for Biofunctional Studies, \\ Universidad Complutense de Madrid (UCM), Spain and Visiting Fellow, Hoover Institution on War, Revolution and \\ Peace, Stanford University USA \\ ${ }^{3}$ Economics Department, Universidad de Montevideo (UM), Uruguay \\ ${ }^{4}$ Legal Medicine Department, Universidad de la República (UDELAR), Violence, Abuse \& Maltreatment Primary \\ Attention, State Health Service Administration (RAP-ASSE), Uruguay \\ ${ }^{5}$ Humanities Department, Universidad de Montevideo (UM), Uruguay
}

\begin{abstract}
This study examines the justification of aggressive acts in Uruguayan children and adolescents in different social situations as a function of age and sex, as well as the effect of differences in socioeconomic status on justification. A total of 663 participants aged 8 to 21 completed a self-report questionnaire designed to measure the justification of eight aggressive acts in six social situations. The results showed that adolescents justified both physical and verbal aggression more easily than children in a wide range of situations. As expected, boys justified physical aggression more easily than girls; however, no differences appeared in regard to verbal aggression. Unexpectedly, no statistically important differences were found in the justification of aggression related to the socioeconomic status of the participants. These findings are discussed in terms of previous studies from other cultures, in the hope of contributing to a deeper knowledge of the complex phenomenon of aggression.
\end{abstract}

Keywords: Aggression, age, sex, socioeconomic status.

\section{INTRODUCTION}

Aggression is a complex concept with multiple aspects. It may be instigated by an overlap of different psychobiological or endogenous circumstances, such as sex or age, and exogenous ones, such as cultural and social factors or situational contingencies $[1,2]$.

O'Connor et al. [3] argued that only a few studies have focused on the age differences in aggression research. Many studies have shown the lowest level of aggression at older ages. In many societies crimes and violence decrease with age, irrespective of the absolute level of violent acts in a particular place [4]. Explanations range from Quetelet's [5] emphasis on declining physical strength (peak of both strength and inter-male homicides between 25-30 years of age) and 'passion' to [6] view that aggression among young men represents reproductive competition arising from sexual selection. Also, a more cautious evaluation of risk and benefit develops gradually with age. Thus, when children arrive to adolescence, they are used to developing sophisticated cognitive and social skills and these begin to

*Address correspondence to this author at the Sociopsychobiology of Aggression Research Group, Psychobiology Department \& Institute for Biofunctional Studies, Universidad Complutense de Madrid (UCM), Spain; Tel: +34 665071234; Fax: +34 913943 069; E-mail: natfares@hotmail.com acquire more subtle and complex forms. Thus, these skills might help them to cope with social difficulties, engaging in fewer conflicts and resolving them more pro-socially. For this reason, Björkvist et al. [7] argued that young children who lack verbal skills are likely to use physical aggression such as hitting, pushing, and kicking- until their verbal abilities develop; then, verbal means of aggression tend to replace physical ones whenever possible, because they are less dangerous than using psychical aggression. Furthermore, Toldos [8, 9], indicated that younger adolescents (14-15 years old) rated higher than older adolescents (16-17 years old) in all types of violence. The development of aggression may be represented as a curve in adolescence, descending only towards the end of this stage. For instance, a peak was found at the age of fourteen for physical aggression [10-12], and at age of eleven for indirect aggression [7, 12, 13]. On the basis of past research and the theoretical considerations discussed earlier, it was predicted that physical aggression would be considered to be more acceptable by children.

Another goal of this study was to replicate some of the earlier data analysing the effect of sex in the justification of aggression. Previous studies also suggested that males are usually more aggressive than females, but with a considerable variability in the following aspects: (1) the magnitude of sex differences, (2) whether a statistically significant sex difference exists, (3) the type of aggression 
studied, (4) the direction of the sex difference [14, 15], and (5) the social representation of aggression: men tend to hold an instrumental representation of aggression (imposing control), whereas women usually have an expressive representation of it (loosing self-control) [16-18]. Males presented higher levels of justification than females did in different combinations of severe aggressive acts and justifying situations [19-22]. A previous study with Spanish University students showed that while boys reported more physical aggression and hostility than girls, the latter preferred verbal aggressive strategies $[20,21]$. Another study with Spanish adolescents indicated that boys justified gender violence more easily as an emotional reaction or a demonstration of power [8, 9]. Furthermore, several studies have demonstrated that girls from different cultures justified the indirect forms of aggression more easily: for instance, in Finland [7], in Australia [23], in Spain and in Japan [24]. A quite recent paper [25] has suggested the existence of a new subcategory of aggression, denominated direct non-verbal aggression, predominant in females; and, after redefining indirect aggression in a strict way (wherein the aggressors hide their identities), they consequently correct the abovementioned considerations about more indirect aggression in females, concluding that no sex differences were found in adult indirect aggression, as it has also been previously stated by other colleagues [26-28]. Thus, girls preferred to express anger and pursue social goals in ways that may prominently feature social aggression rather than physical aggression and other overt expressions of anger. Since females are physically weaker than males in the majority of cases, they may learn to avoid physical aggression early in life. In this study, we expected girls to have a higher score in the justification of verbal aggression for all the situations, because verbal strategies create distance between the opponents and they are less dangerous than physical ones. It was also predicted that boys would consider aggression to be more acceptable in a wider range of situations than girls would.

In addition, we examined the effects of their socioeconomic status, as well as the analysis to its eventual interaction with sex and age in the justification of aggression. A previous study in Spain showed that students from a medium-low socioeconomic status attending public non-religious high schools and students of private religious institutions of medium-upper socioeconomic status justified gender aggression and sexism more easily than their counterparts from private religious schools of a medium-low socioeconomic status $[8,9]$. In the present study in Uruguay, students of public schools: usually from a lower-medium socioeconomic status were compared with students of private schools: usually from a medium-upper socioeconomic status. Although Latin American societies have changed in response to urbanisation, democracy, economic reform and globalisation, they still show an inequitable socioeconomic distribution in comparison to other developed Western countries. Also, income distribution has remained the most inequitable of any continent [29]. Whereas in Europe are usually four poor children for each adult in the same socioeconomic status, in Uruguay the rate shows more than twice as much ( 9 poor children for each poor adult) [30]. Therefore, it was expected that private school students from an upper socioeconomic status would score higher than public school students in the justification of aggression, especially in situations of "protecting own property and reputation", presuming that the latter may have grown up with less sense of private property, given by their poor economic situation.

\section{METHOD}

\subsection{Subjects}

Six hundred and sixty-three Uruguayans (51.73\% females; $48.26 \%$ males), aged 8 to 21 (Mean=14.66, Standard Deviation=2.74), from two primary schools and two high schools in Montevideo (1,340,273 inhabitants) [31] participated in this study. They were grouped in two age cohorts: 205 children (primary students) aged 8 to 14 $(\mathrm{M}=10.94, \quad \mathrm{SD}=1)$, and 458 adolescents (high school students) aged 13 to $21(\mathrm{M}=16.33, \mathrm{SD}=1.2)$ (see: Table 1). The selection of the sample was controlled by three criteria: the level of education (primary vs. high school), the type of education (public vs. private) and the socioeconomic status (low-medium vs. medium-upper). Although children and adolescents were not asked to provide specific information about their parents' level of income, the average income in neighbourhoods of students attending public institutions showed to be lower than in the private system. The monthly

Table 1. Distribution of the Subjects by Age, Sex, and Socioeconomic Status

\begin{tabular}{|c|c|c|c|c|c|c|c|c|c|c|c|}
\hline \multirow{3}{*}{\multicolumn{2}{|c|}{$\begin{array}{c}\text { Total } \\
\text { Sample }\end{array}$}} & \multicolumn{5}{|c|}{ Children (Primary School Students) } & \multicolumn{5}{|c|}{ Adolescents (High School Students) } \\
\hline & & \multirow{3}{*}{$\begin{array}{c}\text { Total } \\
10.94\end{array}$} & \multicolumn{2}{|c|}{ Sex } & \multicolumn{2}{|c|}{ Socioeconomic Status } & \multirow{3}{*}{$\begin{array}{l}\text { Total } \\
16.33\end{array}$} & \multicolumn{2}{|c|}{ Sex } & \multicolumn{2}{|c|}{ Socioeconomic Status } \\
\hline & & & Boys & Girls & Lower & Upper & & Boys & Girls & Lower & Upper \\
\hline Age & 14.66 & & 10.98 & 10.90 & 11.05 & 10.79 & & 16.33 & 16.32 & 16.65 & 16.01 \\
\hline SD & 2.74 & 1.00 & 1.04 & 0.97 & 1.14 & 0.75 & 1.20 & 1.23 & 1.17 & 1.29 & 0.99 \\
\hline Oldest & 21 & 14 & 14 & 14 & 14 & 12 & 21 & 21 & 21 & 21 & 19 \\
\hline Youngest & 8 & 8 & 8 & 8 & 8 & 9 & 13 & 13 & 14 & 14 & 13 \\
\hline Observations & 663 & $31 \%$ & $52 \%$ & $48 \%$ & $58 \%$ & $42 \%$ & $69 \%$ & $47 \%$ & $53 \%$ & $50 \%$ & $50 \%$ \\
\hline
\end{tabular}


average per capita income (salary, transfers from the government, rents and several forms of income) of households in the neighbourhoods of public school students from this sample is approximately 327 US\$, whereas in neighbourhoods where students attended private schools, it is 3.5 times higher (approximately 1,138 US\$) [31].

\subsection{Instrument}

The self-report questionnaire entitled CAMA Cuestionario sobre Actitudes Morales sobre Agresión (Questionnaire on Moral Attitudes towards Aggression) [21, 32], adapted from the original version by Lagerspetz \& Westman [33], was applied. This instrument has been used in application to populations from a wide range of cultures all over the world aged 12 to 90 [1, 34-42]. Participants were asked to respond whether or not they would justify eight kinds of aggressive acts that could take place in six different social situations. A dichotomous format ('Yes' and 'No') was used for all items (see: Appendix A).

\subsection{Procedure and Ethical Aspects}

After consent from the participants and their parents was obtained, the questionnaire was distributed by the researcher to the students, allowing a 30-minute period, approximately, to fill it out in a single session, with the permission of their teachers. The students and their families were informed that this anonymous and voluntary questionnaire dealt with opinions about a series of behaviours and that they would not be penalized in any way if they chose not to respond. Even so, the participants were asked to make an effort and mark all the items. A cover letter explaining the objectives of the study and requesting demographic information about the respondent such as age, sex, educational level and neighbourhood was attached.

\subsection{Variables and Analysis}

Three independent variables were considered: sex, age and socioeconomic status. The dependent variables -8 acts in 6 situations- are specified in Appendix A. The aggressive acts were grouped in two active categories (verbal and physical) and passive aggression. Only the acts of active aggression has been analysed in the present paper. Verbal aggression was defined by the sum of the positive answers to the justification of: "shouting angrily", "being ironical" and "threatening"; Physical aggression was a variable constructed with the sum of the positive answers to the justification of: "killing", "using torture" and "hitting". First, a graphic analysis was done. Then, in order to analyse the interaction of the three variables mentioned on the justification of aggression, a formal statistical analysis based on Ordinary Least Squares regressions was performed. This method allowed the isolation of the effects of age, sex and socioeconomic status. For example, the following was observed: (i) a tendency to justify the use of verbal aggressive acts more easily in older students and (ii) an older average age in students of public institutions than their peers in private ones (maybe it was due to a high level of grade failure or retention in the public sector). Therefore, using both (i) and (ii), there was a mixed effect on the justification of aggressive acts, when comparing students from private vs. public institutions and different ages. Also, a formal regression analysis allowed for the separation of these mixed effects and it determined when statistical differences appeared in previous graphs.

\section{RESULTS}

The Stata/SE 9.2 informatics system and SPSS (Statistical Package for Social Sciences) Windows 17.0 version were used for the statistical analysis. Results were structured in four sections: the analysis of consistency and validation of the CAMA questionnaire in order to use it with the present sample, and the justification of interpersonal aggressive acts related to age, sex and socioeconomic status, respectively. A previous analysis of variances found three types of acts, corresponding to physical and verbal (both active) and passive aggression: [36]. In physical aggression, the noxious stimuli delivered to the victim resulted in physical pain or injury, using physical means or force to damage or to harm another person, whereas verbal aggression was elicited orally, inflicting psychological harm [43-45].

\subsection{Validation of the Moral Attitude toward Aggression Questionnaire (CAMA)}

An evaluation of the internal consistency (or reliability) of the psychometric parameters of the instrument was made. This statistic was related to the consistency of the scales constructed: eight, one for each act ("being ironical", "threatening", "killing", etc.). For example, the scale named "justification of being ironical" is the sum of the answer (yes=1) to the question "In your opinion, is "being ironical" justifiable/admissible, or not, in case of (each of the 6 situations analysed: "self-defence", "for protecting another person", etc.). Each scale has a minimum of 0 and a maximum of 6: the higher scored valued most how a person justified each act. Table 2 shows Cronbach's Alpha for the eight scales, one for each aggressive act: it was higher than 0.70 in all the cases (satisfactory), except in the "justification of using torture" $(0.53)$.

Table 2. Validation of CAMA

\begin{tabular}{|c|l|c|}
\hline CAMA Questionnaire & & Cronbach's Alpha \\
\hline \hline \multirow{4}{*}{ Acts } & Using torture & 0.53 \\
\cline { 2 - 3 } & Killing & 0.71 \\
\cline { 2 - 3 } & Threatening & 0.75 \\
\cline { 2 - 3 } & Hindering & 0.76 \\
\cline { 2 - 3 } & Being ironical & 0.80 \\
\cline { 2 - 3 } & Hitting & 0.81 \\
\cline { 2 - 3 } & Getting furious & 0.83 \\
\cline { 2 - 3 } & Shouting angrily & 0.84 \\
\hline
\end{tabular}




\subsection{Justification of Interpersonal Aggression Related to Age}

The justification of aggression was significantly higher in adolescents than in children at the $1 \%$ level (both sexes). Both Uruguayan populations -children and adolescentsshowed a lower acceptance of physical and drastic forms of aggression ("killing", "using torture") than verbal and passive forms: "getting furious", "being ironical", "hindering", "shouting angrily" (see: Graph 1).

In adolescents, the justification of physical aggression is 1.37 times higher than in children (3.7 vs. 2.7), while the justification of verbal aggressive acts is 1.62 times higher than in children (10.5 vs. 6.5) (see: Graph 2).

Adolescents justified the act "being ironical" more easily $(\mathrm{p}<0.01, \mathrm{t}=31)$, whereas the lowest differences were shown in the justification of "hindering" ( $p<0.05, \mathrm{t}=3)$ and "using torture" ( $\mathrm{p}>0.1, \mathrm{t}=-0.2)$, with no significant differences (see: Table 3).

\subsection{Justification of Interpersonal Aggression between Both Sexes}

Some differences in the approval of aggression were observed between both sexes. In children, boys scored higher than girls in both physical and verbal aggression. But whereas girls showed a $66 \%$ lower justification of physical aggression than boys (significant at the 1\% level), in the case of verbal aggressive acts, although girls still scored lower than boys, the difference was not statistically significant (7.0 vs. 5.9) (see: Graph 3).

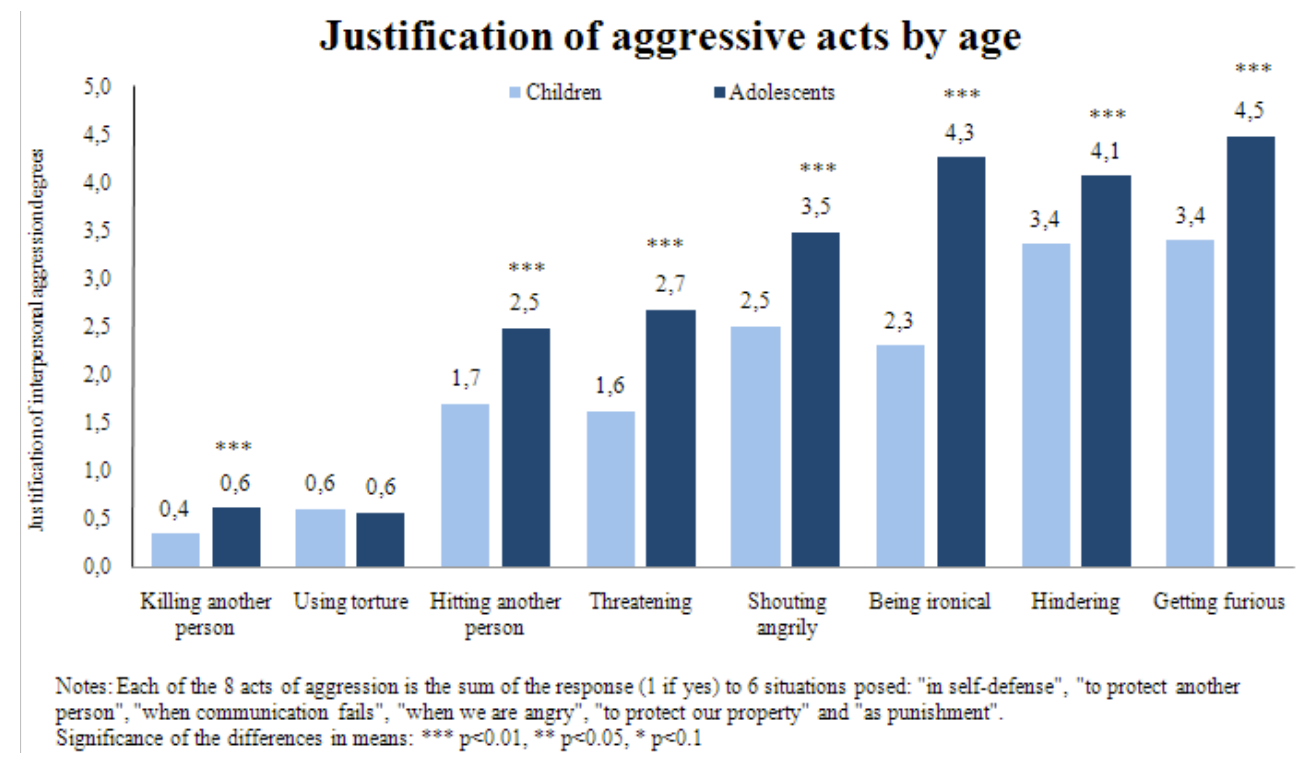

Graph 1. Justification of aggressive acts by age.

\section{Justification of physical vs. verbal aggression by age}

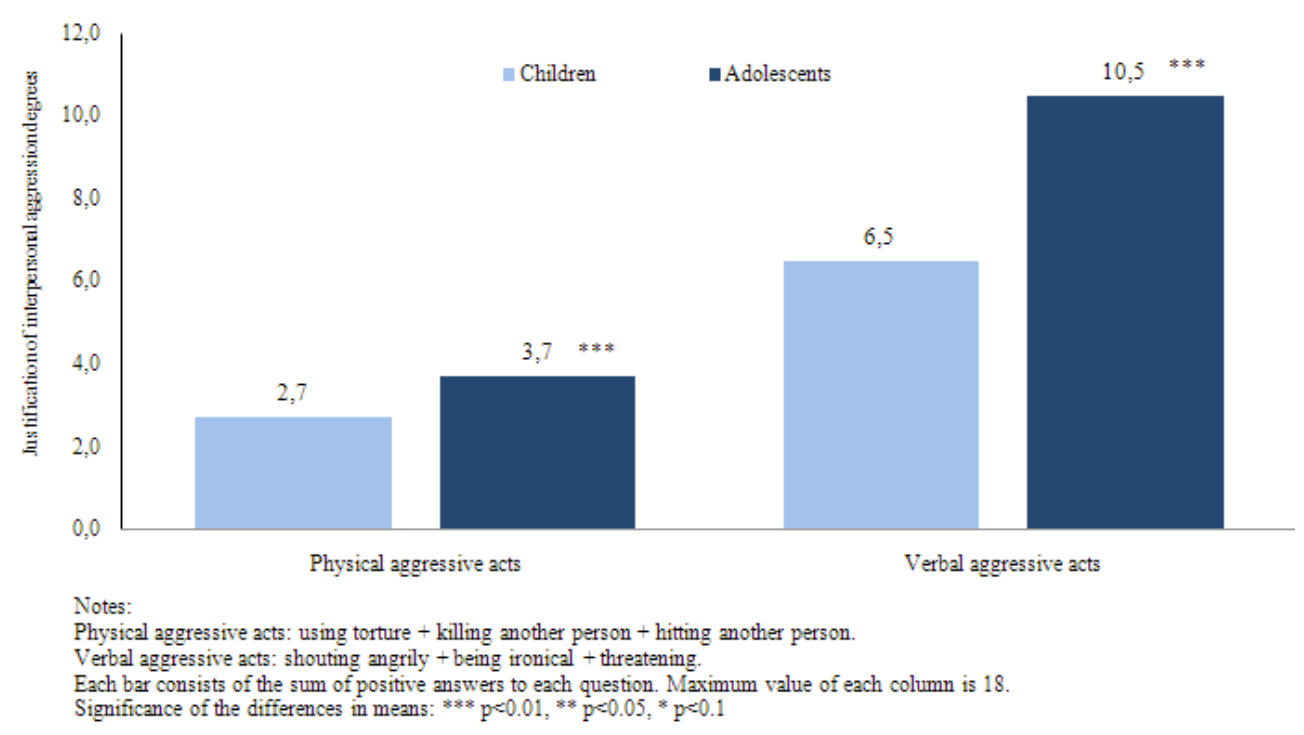

Graph 2. Justification of physical vs. verbal aggression by age. 
Table 3. Justification of Aggressive Acts by Age

\begin{tabular}{|c|c|c|c|c|c|c|c|c|c|c|}
\hline \multicolumn{10}{|c|}{ Justification of Aggressive Acts } \\
\hline \hline & $(1)$ & $(2)$ & $(3)$ & $(4)$ & $(5)$ & $(6)$ & $(7)$ & $(8)$ & $(9)$ & $(10)$ \\
\hline VARIABLES & $\begin{array}{c}\text { Being } \\
\text { ironical }\end{array}$ & Threatening & Hindering & $\begin{array}{c}\text { Using } \\
\text { torture }\end{array}$ & $\begin{array}{c}\text { Shouting } \\
\text { angrily }\end{array}$ & $\begin{array}{c}\text { Hitting } \\
\text { another person }\end{array}$ & $\begin{array}{c}\text { Getting } \\
\text { furious }\end{array}$ & $\begin{array}{c}\text { Killing } \\
\text { another person }\end{array}$ & $\begin{array}{c}\text { Physical } \\
\text { aggressive acts }\end{array}$ & $\begin{array}{c}\text { Verbal } \\
\text { aggresive acts }\end{array}$ \\
\hline Adolescent & $1.946^{* * *}$ & $1.086^{* * *}$ & $0.729 * *$ & -0.012 & $0.980^{* * *}$ & $0.864 * * *$ & $1.086^{* * *}$ & $0.304 * * *$ & $1.157 * * *$ & $4.030^{* * *}$ \\
\hline & 31.207 & 20.699 & 3.013 & -0.245 & 8.234 & 14.524 & 6.511 & 12.448 & 24.579 & 23.970 \\
\hline & {$[0.062]$} & {$[0.052]$} & {$[0.242]$} & {$[0.048]$} & {$[0.119]$} & {$[0.059]$} & {$[0.167]$} & {$[0.024]$} & {$[0.047]$} & {$[0.168]$} \\
\hline Observations & 657 & 662 & 663 & 663 & 663 & 663 & 663 & 663 & 663 & 657 \\
\hline R-squared & 0.199 & 0.123 & 0.034 & 0.038 & 0.081 & 0.146 & 0.067 & 0.074 & 0.136 & 0.169 \\
\hline
\end{tabular}

Notes:

Results are from 8 regressions of the form: $a_{c} t_{i}=$ constant $+b_{1}$ female $+b_{2}$ adolescent $+b_{3}$ medium-upper socioeconomic status $s_{i}+e_{i}$

Columns 1 to 8 : each aggressive act is constructed by the sum of the answer ( 1 if the answer was 'yes') to each of the different social situations.

Columns 9 \& 10: summary of the acts grouped into physical $(4,6,8)$ and verbal aggression $(1,2,5)$.

"Adolescent" denotes the coefficient of a dummy variable taking the value of 1 in the case of an adolescent. Thus, it shows the difference between children and adolescents in the probability of justifying each one of the 8 agressive acts. If the coefficient is positive (and statistically different from zero), then adolescents justify more easily the specific act being studied.

Controls also include sex, socioeconomic status and a constant term.

t-values under the coefficients. Standard errors appear in brackets and are robust to heteroscedasticity and clustered in 5 institutions.

Significance of the coefficients: $* * * \mathrm{p}<0.01, * * \mathrm{p}<0.05, * \mathrm{p}<0.1$.

\section{Justification of physical vs. verbal aggression by sex in children}

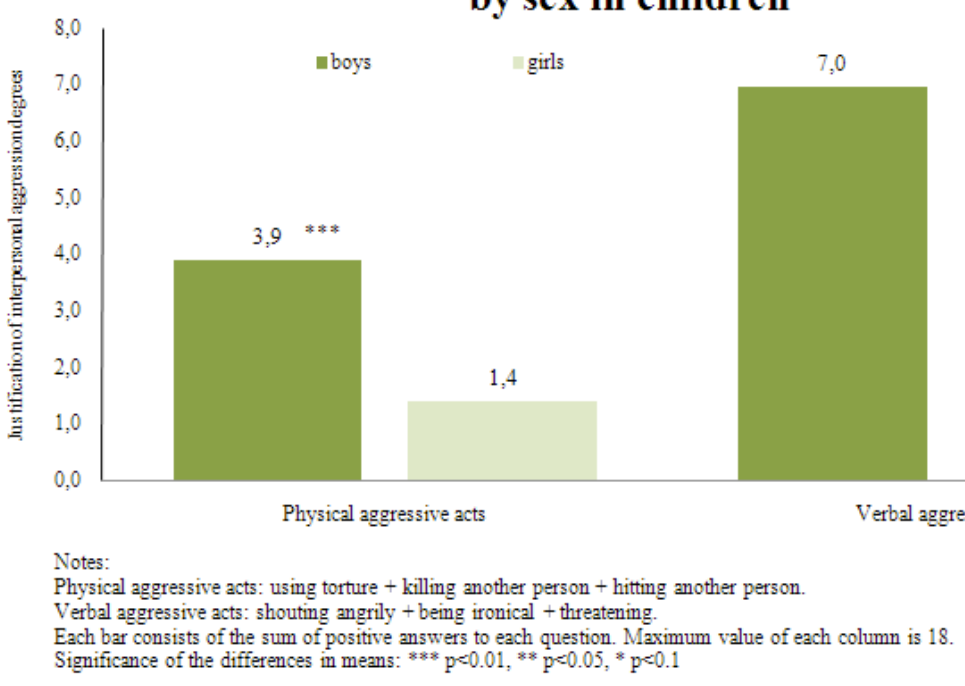

Graph 3. Justification of physical vs. verbal aggression by sex in children.

Among adolescents, boys have shown a higher level of justification than girls for physical aggressive acts, but no significant differences were found related to verbal aggressive acts, although girls scored slightly higher than boys for verbal violence (see: Graph 4).

A regression analysis confirmed that, even controlling age and socioeconomic status, girls justified all physical aggressive acts less than boys $(\mathrm{p}<0.01, \mathrm{t}=-16,7)$ (see: Table 4, column 9), the biggest significant difference being when "hitting another person". However, no statistical differences emerged in the justification of verbal aggressive acts $(p>0.1$, $\mathrm{t}=-0.4$ ) (see: Table 4, column 10). Also, girls justified "shouting angrily" more easily $(\mathrm{p}<0.05, \mathrm{t}=2,99)$ and "threatening" ( $\mathrm{p}<0.01, \mathrm{t}=-9.6)$ less than boys.

\subsection{Justification of Interpersonal Aggression Related to Socioeconomic Status}

Results showed no major differences in the justification of any type of aggression between students of public and private schools in children or in adolescents (see: Graphs 5 and 6).

An interesting difference was observed in relation to the verbal aggressive acts: students of a low-medium socioeconomic status tended to justify more easily emotional acts, such as "shouting angrily" $(\mathrm{p}<0.01, \mathrm{t}=-11.2)$, whereas students of a higher status level justified milder acts such as "being ironical" $(\mathrm{p}<0.05, \mathrm{t}=4.5)$ and "threatening" $(\mathrm{p}<0.05$, $\mathrm{t}=2.8$ ) more easily (see: Table 5). 


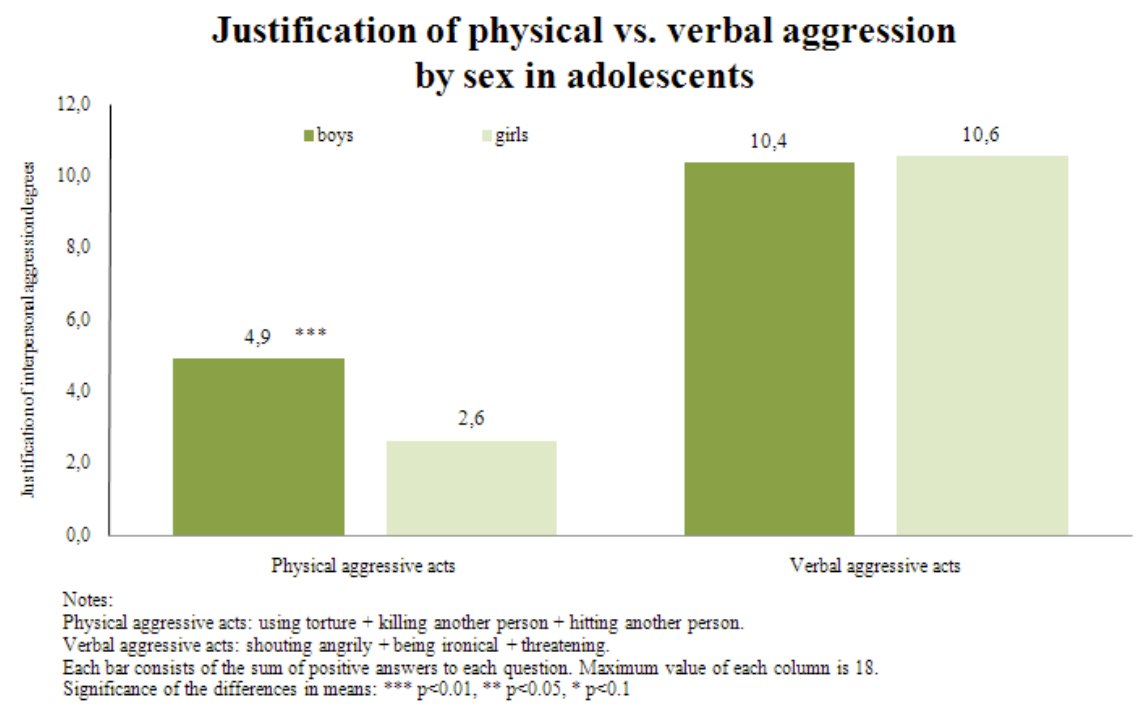

Graph 4. Justification of physical vs. verbal aggression by sex in adolescents.

Table 4. Justification of Aggressive Acts by Sex

\begin{tabular}{|c|c|c|c|c|c|c|c|c|c|c|}
\hline \multicolumn{10}{|c|}{ Justification of Aggressive Acts } \\
\hline \hline & $(1)$ & $(2)$ & $(3)$ & $(4)$ & $(5)$ & $(6)$ & $(7)$ & $(8)$ & $(9)$ & $(10)$ \\
\hline VARIABLES & $\begin{array}{c}\text { Being } \\
\text { ironical }\end{array}$ & Threatening & Hindering & $\begin{array}{c}\text { Using } \\
\text { torture }\end{array}$ & $\begin{array}{c}\text { Shouting } \\
\text { angrily }\end{array}$ & $\begin{array}{c}\text { Hitting another } \\
\text { person }\end{array}$ & $\begin{array}{c}\text { Getting } \\
\text { furious }\end{array}$ & $\begin{array}{c}\text { Killing another } \\
\text { person }\end{array}$ & $\begin{array}{c}\text { Physical } \\
\text { aggressive acts }\end{array}$ & $\begin{array}{c}\text { Verbal } \\
\text { aggresive acts }\end{array}$ \\
\hline Female & -0.103 & $-0.812 * * *$ & -0.084 & $-0.479 * * *$ & $0.717 * *$ & $-1.337 * * *$ & -0.207 & $-0.539 * * *$ & $-2.355 * * *$ & -0.197 \\
\hline & -0.508 & -9.578 & -1.053 & -9.710 & 2.985 & -17.137 & -1.973 & -5.771 & -16.720 & -0.471 \\
\hline & {$[0.203]$} & {$[0.085]$} & {$[0.080]$} & {$[0.049]$} & {$[0.240]$} & {$[0.078]$} & {$[0.105]$} & {$[0.093]$} & {$[0.141]$} & {$[0.418]$} \\
\hline Observations & 657 & 662 & 663 & 663 & 663 & 663 & 663 & 663 & 663 & 657 \\
\hline R-squared & 0.199 & 0.123 & 0.034 & 0.038 & 0.081 & 0.146 & 0.067 & 0.074 & 0.136 & 0.169 \\
\hline
\end{tabular}

Notes:

Results are from 8 regressions of the form: $a_{i} t_{i}=$ constant $+b_{1}$ female $+b_{2}$ adolescent $+b_{3}$ medium-upper socioeconomic status ${ }_{i}+e_{i}$

Columns 1 to 8 : each aggressive act is constructed by the sum of the answer ( 1 if the answer was 'yes') to each of the different social situations.

Columns $9 \& 10$ : summary of the acts grouped into physical $(4,6,8)$ and verbal aggression $(1,2,5)$.

"Female" denotes the coefficient of a dummy variable taking the value of 1 in case of a girl. Thus, it shows the difference between boys and girls in the probability of justifying each one of the 8 aggressive acts. If the coefficient is negative (and statistically different from zero), then girls score lower than boys in the specific act being studied.

Controls also include being adolescent, socioeconomic status and a constant term.

t-values under the coefficients. Standard errors appear in brackets and are robust to heteroscedasticity and clustered in 5 institutions.

Significance of the coefficients: $* * * \mathrm{p}<0.01, * * \mathrm{p}<0.05, * \mathrm{p}<0.1$.

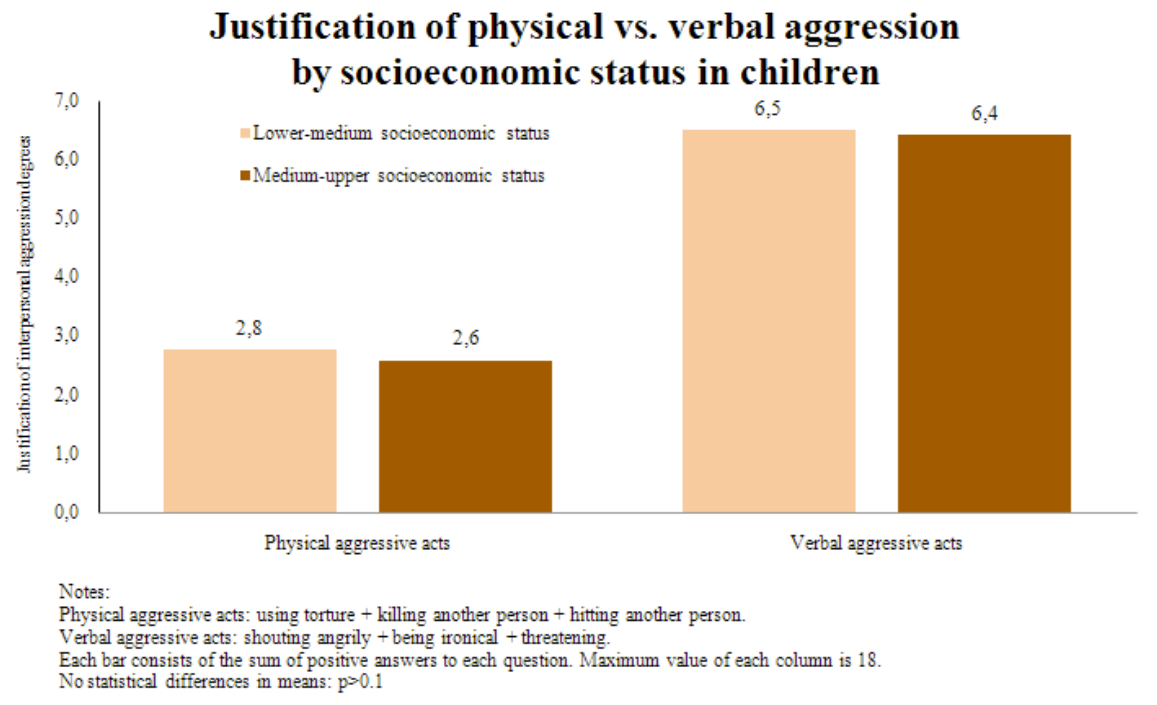

Graph 5. Justification of physical vs. verbal aggression by socioeconomic status in children. 


\section{Justification of physical vs. verbal aggression by socioeconomic status in adolescents}

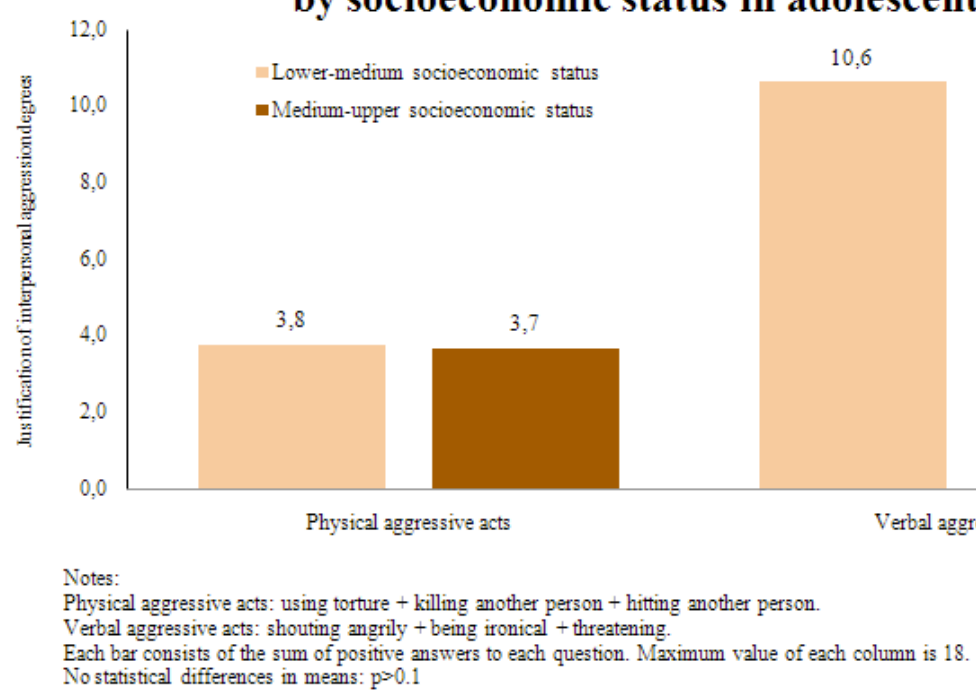

Graph 6. Justification of physical vs. verbal aggression by socioeconomic status in adolescents.

Table 5. Justification of Aggressive Act by Socioeconomic Status

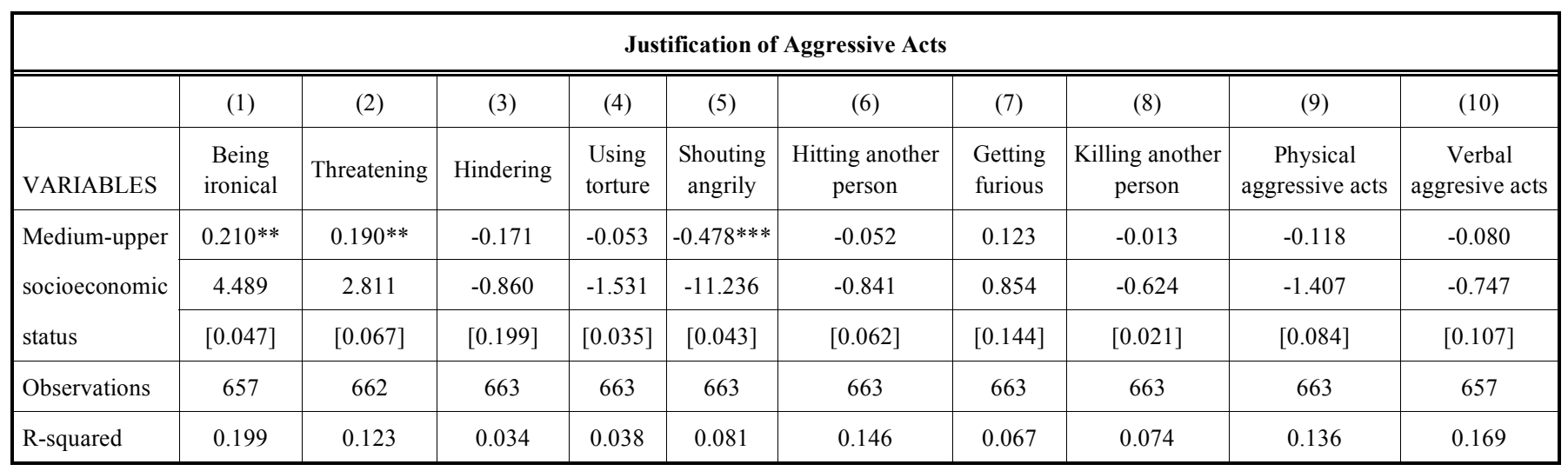

Notes:

Results are from 8 regressions of the form: $a t_{i}=$ constant $+b_{1}$ female $+b_{2}$ adolescent $+b_{3}$ medium-upper socioeconomic status $s_{i}+e_{i}$

Columns 1 to 8: each aggressive act is constructed by the sum of the answer ( 1 if the answer was 'yes') to each of the different social situations.

Columns 9 \& 10: summary of the acts grouped into physical $(4,6,8)$ and verbal aggression $(1,2,5)$.

"Medium-upper socioeconomic status" is a dummy variable taking the value of 1 in case of a student of a private school or high school. The coefficient indicates how much more (if the coefficient has positive sign) a student of an upper socioeconomic status justifies an aggressive act than a student of a lower socioeconomic status.

Controls also include sex, being adolescent and a constant term.

t-values under the coefficients. Standard errors appear in brackets and are robust to heteroscedasticity and clustered in 5 institutions.

Significance of the coefficients: $* * * \mathrm{p}<0.01, * * \mathrm{p}<0.05, * \mathrm{p}<0.1$.

\section{DISCUSSION}

Similarly to previous data recorded in other cultures [36, 42], Uruguayan children and adolescents justified drastic forms of aggression ("killing", "using torture") less than the milder aggressive acts ("stopping somebody from doing something", "being ironical"). Also, there was a higher acceptance of aggression in socially justified situations (for instance: in terms of protection of self or other) than where there was no such justification (communication problems). However, a quite striking difference was found when comparing the Uruguayan adolescents' sample to their counterparts of similar age from other countries: they showed a higher level of acceptance of aggression than did the Spanish, Chinese and Cambodian adolescents. Uruguayan male adolescents showed the highest score for emotional, unplanned and "bloody" acts as well as instrumental, planned and "cold" aggression compared to adolescents from the above-mentioned countries".

Contrary to the prediction that physical aggression would be considered to be more acceptable by children than by adolescents, this study showed that adolescents justified physical and verbal aggression more easily than children,

\footnotetext{
* Alvarado, J. Personal communications, 2011
} 
confirming some differences related to age previously pointed by Toldos $[8,9,46]$ adolescents showed a higher justification of aggression against authority and peers, and in the use of violence. The results confirmed that males had a higher aggressiveness [7, 23, 44] and justified aggression more easily and in a wider range of situations $[8,9,20,21$, $36,47]$ than females. Bonino and Fraczek [48] also founded a higher approval of all kinds of antisocial behaviours in boys. In our study, boys justified the most drastic kinds of aggression -using physical aggressive acts- more than girls in all the social situations. On the other hand, the data of this study differed from previous studies with Spanish university students, in which boys also justified verbal aggression higher than girls [21]. Thus, no differences between sexes were found for verbal aggressive acts, such as "getting furious", "shouting" or "being ironical". Sex differences may be explained not only by biological factors, but also by social expectations, representations and stereotypes: positive attitudes toward violence (tolerance and frustration) when expressed by males and negative attitudes when by females [47].

In contrast with previous studies, no major differences in the justification of aggression was shown related to the socioeconomic status of children and adolescents. However, some minor but interesting differences appeared in the justification of verbal aggressive acts; for instance, adolescents of a medium-high socioeconomic status scored higher in the acceptance of milder acts such as "threatening" or "being ironical", than other apparently less 'polite' ones, such as "shouting".

To sum up, this study confirmed that sex and age are important variables in the justification of different quality and intensity of aggression. In addition to these psychobiological constraints, social and cultural factors may also influence the socialization of aggression in the course of the individual's development, as well as the dynamics of violence in everyday social life $[48,49]$. In this context, a limitation of this study could be that the family context was not considered; this would be an important line for future research. Another possible further study could consist in linking the academic and social outcomes e.g. at school and peer acceptance. A second limitation was that potential neurological or psychiatric disorders were not analysed, and in many cases no medical diagnoses had been presented. This issue has been alarming the health authorities in our society, given its prevalence and relationship to behaviour disorders and violence.

More empirical work is also necessary on the validity of alternative measurement in the study of different types of aggression in different cultures and family background, including other age cohorts (e.g. preschoolers), as well as specific sub-populations. For instance, these questions could be addressed in high-risk samples such as people with psychological disorders and criminal delinquents [50-53]. Finally, further research is needed in order to implement adequate comprehensive programs of diagnosis, inter- vention, prevention and treatment of violence and behaviour disorders in children and adolescents.

\section{CONCLUSIONS}

- Similarly to the conclusion of the studies in other cultures, Uruguayan children and adolescents showed a lower acceptance of active forms of aggression than passive forms.

- Unexpectedly, adolescents showed a higher justification of aggression than children, especially related to the verbal aggression.

- As expected, boys justified physical aggressive acts more easily than girls, but contrary to previous observations, girls did not score higher than boys in the justification of verbal aggressive acts.

- Unexpectedly, there were no statistically important differences in the justification of physical and verbal aggressive acts among students from different socioeconomic status.

- Further research is needed to analyse the justification of aggressive acts and the probability of using violence against peers and authority, as well as the relationship between that justification, socialization, and the moral attitudes towards different aggression types. Moreover, it could be relevant to investigate the confluence of the justification of aggression, the above-mentioned variables and the neuropsychological development in regard to language learning, intellectual skills, abstract reasoning, executive functions and self-regulation.

- These findings suggest the need of reducing the adolescents' tendency to justify aggression and to use violence through prevention and intervention programs, and to focus especially on boys.

\section{CONFLICT OF INTEREST}

None Declared.

\section{ACKNOWLEDGEMENTS}

The research was conducted as part of the doctoral studies of the senior author at the Psychobiology Department of the Complutense University of Madrid. It was carried out with the support of a scholarship from MAEC (Ministerio de Asuntos Exteriores y de Cooperación or the Ministry of Foreign Affairs and Cooperation, Spanish Government) and AECID (Agencia de Cooperación Internacional para el Desarrollo or the Spanish Agency for International Development Cooperation). A previous report of this research was presented at the XXX CICA, held at Leányfalu (Hungary), 26-29th August 2010. The authors acknowledge the invaluable help in the collection of the data by the staff of several public and private schools from Montevideo (Uruguay), who preferred to remain anonymous. Also, the authors thank two anonymous referees for their helpful comments on an earlier draft of this paper. 


\section{APPENDIX: CAMA}

(Questionnaire on Moral Attitudes toward Aggression)

C J. Martin Ramirez (1985)

List of situations

1. IN SELF-DEFENCE

2. TO PROTECT ANOTHER PERSON

3. WHEN COMMUNICATION BREAKS DOWN

4. WHEN ANGRY

5. TO PROTECT ONE'S PROPERTY

6. AS PUNISHMENT

List of aggressive acts

1. BEING IRONICAL

2. THREATENING

3. STOPPING SOMEBODY

FROM DOING SOMETHING

4. USING TORTURE

5. SHOUTING ANGRILY

6. HITTING

7. GETTING FURIOUS

8. KILLING

\section{REFERENCES}

[1] Andreu J, Ramírez J, Raine A. Un modelo dicotómico de la agresión: valoración mediante dos autoinformes (CAMA y RPQ). Psicopatología Clínica, Legal y Forense 2006; 6; 25-42.

[2] Ramírez J. Hormones and aggression in childhood and adolescence. Aggression Violent Behav 2003; 8(6): 621-44.

[3] O'Connor D, Archer J, Wu F. Measuring aggression: Self-reports, partner reports, and responses to provoking scenarios Aggr Behav 2002; 27(2):79-101.

[4] Archer J. Sex differences in aggression between heterosexual partners: a meta-analytic review. Psychol Bull 2000; 126(5): 651-80.

[5] Quetelet A. Sur l'homme et le développement de ses facultés ou Essai de Physique Social. París: Bachelier 1835.

[6] Wilson R, Moore N. The role of sexually-oriented stimuli in advertising: theory and literature review In: William L Wilkie, Ed. Advances in Consumer Research, Volumen 06. Ann Abor: Association for Consumer Research 1979; pp. 55-61.

[7] Björkqvist K, Lagerspetz K, Kaukiainen A. Do girls manipulate and boys fight? Developmental trends in regard to direct and indirect aggression. Aggr Behav 1992; 18: 117-27.

[8] Toldos M. Adolescencia, violencia y género. Madrid: Publicaciones Universidad Complutense de Madrid 2005.

[9] Toldos M. Sex and age differences in self- estimated physical, verbal and indirect aggression in Spanish adolescents. Aggr Behav 2005; 31: 12-2.

[10] Loeber R. The stability of antisocial and delinquent child behaviour: a review. Child Develop 1982; 53(6): 1431-46

[11] Lindeman M, Harakka T, Keltikangas L. Age and gender differences in adolescents' reactions to conflict situations: Aggression, prosociality, and withdrawal. J Youth Adolescence 1997; 26(3): 339-51.

[12] Österman K, Björkqvist K, Lagerspetz K, et al. Cross-cultural evidence of female indirect aggression. Aggr Behav 1998; 24(1): 1-8.

[13] Lagerspetz K, Björkqvist K, Björkqvist H, Lundman H. Moral approval of aggression and sex role identity in officer trainees, conscientious objectors to military service, and in a female reference group. Aggr Behav 1988; 14: 303-13.

[14] Bettencourt B, Miller N. Gender differences in aggression as a function of provocation: a meta-analysis. Psychol Bull 1996; 119(3): 422-47

[15] Knight G, Fabes R, Higgins D. Concerns about drawing causal inferences from meta-analyses: an example in the study of gender differences in aggression. Psychol Bull 1996; 119: 410-21.

[16] Archer J, Parker S. Social representation of aggression in children. Aggr Behav 1994; 20: 101-14.

[17] Campbell A, Muncer S. Models of anger and aggression in the social talk of women and men. J Theory Soc Behav 1987; 17: 489-512.
[19] Harris M. Effects of sex of aggressor, sex of target, and relationship on evaluations of physical aggression. J Interpersonal Violence 1991; 6: 174-186.

[20] Ramírez J. Similarities in attitudes toward interpersonal aggression in Finland, Poland, and Spain, J Soc Psychol 1991; 13: 737-9.

[21] Ramírez J. Acceptability of aggression in four Spanish regions and a comparison with other European countries. Aggr Behav 1993; 19: 185-97.

[22] Ramírez J, Andreu J, Fujihara T. Cultural and sex differences in aggression: a comparison between Japanese and Spanish students using two different inventories. Aggr Behav 2001; 27: 313-22

[23] Owens L. Stics and stones and sugar and spice: girls and boys aggression in schools. Australian J Guid Cousenll 1996; 6: 45-55.

[24] Ramírez J. Moral approval of aggressive acts by urban students: a cross-national study of four continents. In: Ramírez J, Richardson D, Eds. Cross-cultural approaches to aggression and reconciliation. Huntington: Nova Science Publishers 2001; pp.61-71.

[25] Schober G, Björqvist K, Somppi S. Identifying a new subcategory of aggression: sex differences in direct non verbal aggression. Aggr Conflict Peace Res 2009; 1(3): 58-70.

[26] Forrest S, Eatough V, Shevlin M. Measuring adult and indirect aggression: the development and psychometric assessment if the indirect aggression scales. Aggr Berhav 2005; 31(1): 84-97.

[27] Green L, Richardson D, Lago T. How do friendship, indirect and direct aggression relate? Aggr Behav 1996; 22(2): 81-6.

[28] Richardson D, Green L. Social sanction and threat explanations of gender effects on direct and indirect aggression. Aggr Behav 1999; 25(6): 425-34.

[29] O.E.C.D. Latin American Economic Outlook, 2010. Available from http://www.latameconomy.org/en/outlook/

[30] De Armas, G. Sustentabilidad social. Estrategia Nacional para la Infancia y la Adolescencia 2010-2030. Consejo Nacional de Políticas Sociales. Comité de coordinación estratégica de infancia y adolescencia, Montevideo 2008. Available from: www.enia.org.uy; http://www.enia.org.uy/pdf/Sustentabilidad\%20SOCIAL.pdf

[31] Instituto Nacional de Estadística. INE.2009. Available from http://www.ine.gub.uy/biblioteca/uruguayencifras2009/02\%20Pobl aci\%F3n.pdf

[32] Ramírez J, Folgado L. Attitudes toward aggression in four Spanish regions. Parma: III European I.S.R.A 1985.

[33] Lagerspetz K, Westman M. Moral approval of aggressive acts: a preliminary investigation. Aggr Behav 1980; 6: 119-30.

[34] Fares N, Reyes I, Halty L, Ramírez J. Cultural and sex differences in aggression: comparison between university students from different countries living in Spain, using CAMA and RPQ questionnaires. Bodrum: 28th C.I.C.A. on Attitudes toward Conflict and Aggression 2009. 
[35] Fares N, Lozano F, Cabrera J, Salas F, Ramírez J. Justification of interpersonal aggression in Uruguayan children and high school students from different socio-economic strata, measured by CAMA and RPQ questionnaires. In: Szegál BA, Ed. Conflict and aggression in a society in transition. Leányfalu 2010; pp. 11-12

[36] Ramírez J, Andreu J, Fujihara T. Cultural and sex differences in aggression: a comparison between Japanese and Spanish students using two different inventories. Aggr Behav 2001; 27(4): 313-22.

[37] Musazadeh Z. Agresión y su Justificación: un estudio comparado de estudiantes iraníes y españoles. Madrid: Publicaciones Universidad Complutense de Madrid 1999.

[38] Fujihara T, Kohyama T, Andreu J, Ramírez J. Justification of interpersonal aggression in Japanese, American and Spanish students. Aggr Behav 1999; 25: 185-95.

[39] Fraçzek A. Moral approval of aggressive acts - Polish Finnish coparative study. J Cross Cult Psychol 1985; 16: 41-54.

[40] Fraçzek A, Ramirez J, Torchalska B. Attitudes toward interpersonal aggression. In: Multidisciplinary approach to conflict and appeasement in animals and men. Le Moli F, Ed. Italy: Istituto di Zoología 1987; p. 187.

[41] Ramírez J. Comparison of the degree to which aggression is acceptable in four Spanish regions. Chicago: 7th Biennial Meeting of ISRA 1986.

[42] Ramírez J. Justification of aggression in several Asian and European Countries with different religious and cultural background. Int $\mathbf{J}$ Behav Develop 2007; 31(1): 9-15.

[43] Berkowitz L. Agresión, Causas, consecuencias y control. Bilbao: Desclée de Brouwer 1996.
[44] Björkvist K. Sex differences in physical, verbal and indirect aggression: a review of recent research. Sex Roles 1994; 30: 177-88.

[45] Parrott D, Giancola P. Addressing The criterion problem in the assessment of aggressive behavior: development of a new taxonomic system. Aggr Violent Behav 2007; 12(3): pp. 280-99.

[46] Toldos M. Effects of sex and status of target and aggressor on adolescents' justification of aggression. In: Österman K, Björkqvist K, Eds. Contemporary research on aggression. Finland,Vasa: Äbo Academy University 2006; pp. 64-8

[47] Ramírez J. The Usefulness of Categorizing Aggression according its Function. Int Soc Sci J 2010; 61: 65-74.

[48] Bonino S, Fraczek A. Antisocial behaviour and attitudes toward it in Italian and Polish adolescents. Strasbourg: 12th Biennial Meeting of I.S.R.A 1996.

[49] Fraczek A. Violence and aggression in children and youth: a sociopsychological perspective. Eur Rev 1996; 4: 75-90.

[50] Ramírez J. Some dichotomous classifications of aggression according to its function. J Organisation Transform Soc Change 2009; 6 (2): 85-101

[51] Ramírez J, Millana L, Toldos M, Bonniot M, Cabanac M. The pleasure of being aggressive in male incarcerated criminals. Open Criminol J 2009; 2 (2): 1-9.

[52] Millana L, Cabanac M, Toldos M, Bonniot M, Ramírez J. Placer asociado con la conducta agresiva en una muestra de reclusos españoles en prisión preventiva. Psicopatología Clínica, Legal y Forense 2006; 5: 119-32.

[53] Cabanac M, Ramírez J, Millana L, Toldos M, Bonniot M. The pleasure of aggressiveness among inmates in preventive and longterm detention. Open Criminol J 2008; 1(2): 19-26.

(C) Fares et al.; Licensee Bentham Open.

This is an open access article licensed under the terms of the Creative Commons Attribution Non-Commercial License (http://creativecommons.org/licenses/by-nc/3.0/) which permits unrestricted, non-commercial use, distribution and reproduction in any medium, provided the work is properly cited. 